\title{
PEST Framework for Analysing Cloud Computing Adoption by Mauritian SMEs
}

\author{
Mira Antoo, Zarine Cadersaib, and Baby Gobin
}

\begin{abstract}
SMEs are facing huge competition on the market and must absolutely find means to become visible online. Cloud offers a technological platform for business management. In Mauritius, there are about 100,000 registered SMEs with the Small and Medium Enterprises Development Authority (SMEDA), which provides a range of assistance including information on technological innovations. Currently, the SMEDA has a cloud platform: a server hosted by a third party but is only used for its website. SMEDA's aim is to come up with a better-computerized approach to become more efficient. As per the latest budget report of Mauritius, the SMEDA has the aim of making full use of the cloud to make SMEs become visible. No research is being done currently by SMEDA in terms of cloud computing and its suitability for SMEs and the different segments. In this paper, a literature review is performed on SMEs with respect to ICT adoption and cloud computing. An overview of existing work done on cloud computing and SMEs in general is then carried out using the PEST analysis. The latter is then performed for Mauritian SMEs where a PEST framework is proposed and the results are discussed.
\end{abstract}

Index Terms-Cloud framework, cloud computing and SMEs, SMEs cloud adoption.

\section{INTRODUCTION}

SMEs are said to be the lifeblood of any vibrant economy in a country. They are the silent drivers of a nation's economy. The only way for them to survive in the economy is by remaining competitive. Cloud computing consists of services that are made available on the internet, from software to hardware services at a relatively low cost and gives SMEs an opening to international markets. If implemented correctly, Cloud computing has a high potential in contributing to successful project management. Small and medium sized businesses can take a lot of benefits from embracing business cloud solutions. Cloud platforms allow SMEs to compete in the cloud giant-controlled environment, and gives the level playing field required to succeed in business [1].

SMEs in Mauritius play a massive role in the development of the economy. According to statistics, SMEs contribute to $37 \%$ of GDP, produce some 120 billion Mauritian rupees worth of output annually and employ 250000 men and women [2]. Nowadays there is a significant discussion about globalization of SMEs. For the success of SMEs, there is a need to reframe the strategies, planning and methodologies; thereby requiring an in-depth analysis of the external factors affecting cloud adoption by SMEs. The SMEDA currently

Manuscript received May 25, 2014; revised July 27, 2014

The authors are with the University of Mauritius, Mauritius (e-mail: mira.antoo1@umail.uom.ac.mu, b.gobin@uom.ac.mu). has a cloud platform which is not used efficiently and the authority wants to make full use of the cloud platform. In line with the budget report of Mauritius of 2013 [2], the SMEDA has the aim of making full use of the cloud to make SMEs become visible. It is therefore important to understand the factors which can affect technology adoption and subsequently cloud adoption by Mauritian SMEs.

\section{LITERATURE REVIEW}

Due to the specific requirements and characteristics of smaller organizations (such as number of employees and budget) compared to larger corporates, the attitude of the SMEs towards new IT technologies are normally more conservative than that of their bigger counterparts. In this section, existing research studies addressing the factors that influence adoption of new IT technologies by SMEs are reviewed. Brodkin [3] has conducted a research study to identify factors that impact the effective adoption of new IT trends by SMEs. As a result of that, three major IT acquisition phases and their significance have been identified. Similarly, the relationship between a number of contextual factors, including the CEO's innovativeness, IT knowledge and attitude towards new IT technologies, and IT adoption in SME organizations have been studied [4], [5]. Furthermore, Syed Alam [6] has examined the influence of five major influences in adopting new IT solutions by SMEs. The five investigated factors are 1) perceived benefits 2) perceived cost 3) ICT knowledge and skill 4) external pressures and 5) government supports. The researcher concluded that the perceived benefits of an ICT solution have greatest impact of the adoption decision.

Limitations in the availability of financial and human resources have delayed SMEs in adopting new technologies [7], specifically, during its early stages [8]. This is especially true considering less complex IT requirements of SMEs compared to their larger counter parts [8]. On the other hand, the studies [4], [8]-[11] reveal that SMEs are normally interested in outsourcing their IT requirements in order to be able to focus more on their own core business space [12]. This could make cloud computing an attractive option for SMEs [10]. The exact definition of cloud computing varies from different perspectives. When considering different characteristics and aspects of cloud, there exist more than 20 different definitions [13]. A formal definition is provided by the National Institute of Standards and Technology (NIST) that is considered as one of the most cited definitions for cloud computing (and is used as a reference in this study). According to NIST, "cloud computing is a model for enabling ubiquitous, convenient, on-demand network access to a shared pool of configurable computing resources (e.g. 
networks, servers, storage applications, and services) that can be rapidly provisioned and released with minimal management effort or service provider interaction" [13]. Chang et al. [14] categorize cloud business models into 8 groups based on the need to align business strategies to cloud models for the purposed of long term sustainability. The research studies [4], [10] summarize the advantages and disadvantages of cloud solutions for SMEs. Accordingly, the advantages can be listed as cost reduction; respond to business requirements; easier administration and maintenance; and global access [3], [7], [10].

\section{SMES IN MAURITIUS}

In Mauritius, SMEs are defined as enterprises with an annual turnover not exceeding 50 million rupees [15]. The country has about 100,000 registered SMEs in manufacturing and service sectors [15] categorized in different segments. The government in Mauritius has always supported SMEs since the import-substitution period of the 1960s [2]. The Small and Medium Enterprises Development Authority (SMEDA) was set up in 2009 [2]. SMEDA provides a range of assistance to SMEs covering business counseling, business facilitation, training and marketing support. In addition, recent initiatives include the support to creative craft incubators, as well as establishment of the SME Resource and Technology Center. The latter was launched in 2012 [2], aiming to provide support to SMEs in search of information on recently developed technological innovations that added value to their business activities. Such support includes personal coaching and online technical training on new technologies by local and foreign trainers through proper information channels [2].

Currently, the SMEDA has a cloud platform, which is a server hosed by a third party provider. However, the authority is not making full use of the cloud platform apart from hosting its website and contact details of SMEs in Mauritius. All information about SMEs are presently stored in excel files on the server. There is no proper means of segmentation of information for the time being. However, the SMEDA is looking forward to come up with a better-computerized approach with the use of cloud to become more efficient. As per the budget report of Mauritius of 2013 [2], the SMEDA has the aim of making full use of the cloud to make SMEs become visible. No research is being done in terms of cloud computing and suitability for SMEs and the different segments.

\section{OVERVIEW OF EXISTING WORK ON CLOUd COMPUTING AND SMES}

This section presents the method used to identify existing literature which discuss the adoption of cloud computing and SMEs. Existing papers were reviewed so as to identify which factors are considered to be very important for the adoption of cloud computing using scoping reviews. Scoping reviews are the most appropriate $R \& D$ methodology for [16]: assessing the breadth of R\&D activities, carried out in a specific domain from the depth; summarizing and disseminating research results; identifying gaps in existing research and published scientific literature. Taking these studies as illustrative of the application of scoping reviews, it is an appropriate methodology to discover the evidence available in the literature concerning cloud-computing adoption. The application of this methodological approach and the method used to collect the data is shown in the following subsection. Each paper identified was then evaluated against factors, which are based on the PEST framework [17].

The analysis in this section addresses the following research question:

- What are the key factors that should be considered by SMEs when making the strategic choice to adopt cloud computing as an ICT solution?

\section{A. Paper Selection}

With regards to the research questions and the subsequent PEST (Political, Economic, Social and technological) analysis, the keywords used, together with their equal and related terms, are those shown in the search strings developed. Table I shows the keywords searched.

TABLE I: SEARCH KEYWORDS

\begin{tabular}{|l|l|}
\hline Source & Keywords \\
\hline $\begin{array}{l}\text { ISI web of Knowledge } \\
- \text { Web of Science }\end{array}$ & Cloud AND SME \\
\hline Google Scholar & $\begin{array}{l}\text { Cloud Computing AND Technology adoption } \\
\text { AND (SME OR small and medium enterprises) }\end{array}$ \\
\hline IEEE Xplore & $\begin{array}{l}\text { Cloud AND Adoption AND SME } \\
\text { Cloud and SMEs }\end{array}$ \\
\hline
\end{tabular}

The searches were limited to English language documents, within the timeframe of 2010 to 2014. The following rejection criteria were used for filtering:

- Paper(s) out of context

- Paper(s) addressing only one viewpoint

- References to abstracts and table of contents only

Table II is the outcome of the papers used after applying the above criteria.

TABLE II: RETRIEVED VERSUS REJECTED PAPERS

\begin{tabular}{|l|l|l|l|}
\hline Database & Results & Excluded & Analyzed \\
\hline Web of Science & 13 & 9 & 4 \\
\hline Google Scholar & 12 & 7 & 5 \\
\hline IEEE & 39 & 31 & 8 \\
\hline TOTAL & 64 & 47 & 17 \\
\hline
\end{tabular}

\section{B. PEST Analysis}

To address the research question and discover some of the main factors that should be considered by SMEs when considering the strategic decision to adopt cloud computing, an analysis of 17 papers ([2], [12], [17], [18]-[31]) retrieved based on the PEST framework was performed. The headings in the four quadrants in PEST analysis also gives a framework for reviewing the situation and describing why these factors are particularly relevant to the business processes of SMEs. The main results of the PEST analysis for the adoption of cloud computing by SMEs are shown in Table III - Table VI.

Table III summarizes the political part of the analysis. It can be seen that the data protection and legislation are highly influential factors for SMEs all researchers are agreeable to this. A few researchers found that favorable tax treatments by the government as well as government initiatives do accelerate IT adoption. In the Mauritian context, this is highly relevant as SMEs are driven to adopt cloud when they are 
being given a free of cost platform to begin. As a fact, from the Mauritian report budget 2013, the government aims to promote SMEs on the cloud by giving a free initial website to each SME, in line with the sustainable development of the country.

TABLE III: POLITICAL ANALYSIS

\begin{tabular}{|l|c|c|c|c|c|c|}
\hline \multicolumn{1}{|c|}{ Reference } & [12] & [19] & [23] & [24] & [25] & [26] \\
\hline Analysis criteria & $\checkmark$ & $\checkmark$ & $\checkmark$ & $\checkmark$ & $\checkmark$ & $\checkmark$ \\
\hline Legislations Protection & $\checkmark$ & $\checkmark$ & $\checkmark$ & $\checkmark$ & $\checkmark$ & $\checkmark$ \\
\hline $\begin{array}{l}\text { Initiatives to } \\
\text { accelerate SMEs use } \\
\text { of internet }\end{array}$ & & $\checkmark$ & & $\checkmark$ & & \\
\hline $\begin{array}{l}\text { Favorable tax } \\
\text { treatment }\end{array}$ & & $\checkmark$ & & $\checkmark$ & & \\
\hline $\begin{array}{l}\text { Sustainable } \\
\text { development concept }\end{array}$ & $\checkmark$ & & & & & \\
\hline
\end{tabular}

A country's economic situation impacts directly on IT adoption, especially by the niche market. As a fact, Table IV reveals the different factors SMEs are most likely to consider before considering cloud adoption. According to researchers, price, security and cost are the main economic factors that influence SMEs. Mauritius has known a stable economic situation since the last decade. SMEs are more and more interested to improve while keeping down cost and investing on secure affordable technologies. Besides, the Mauritian government sensitizes a lot on sustainable development, whereby the green technology factor is being considered by SMEs.

\begin{tabular}{|l|c|c|c|c|c|c|}
\hline \multicolumn{1}{|c|}{ TABLE IV: ECONOMIC ANALYSIS } \\
\hline Analysis criteria & [12] & [18] & [19] & [20] & [21] & [22] \\
\hline Affordable price & $\checkmark$ & $\checkmark$ & $\checkmark$ & $\checkmark$ & $\checkmark$ & \\
\hline Costs reduction & $\checkmark$ & $\checkmark$ & $\checkmark$ & $\checkmark$ & & \\
\hline $\begin{array}{l}\text { Competitive } \\
\text { advantage }\end{array}$ & & & $\checkmark$ & & & \\
\hline $\begin{array}{l}\text { Green technology } \\
\text { concept promotes an } \\
\text { increase in } \\
\text { productivity }\end{array}$ & & & & & & $\checkmark$ \\
\hline Better security & & $\checkmark$ & $\checkmark$ & $\checkmark$ & & \\
\hline $\begin{array}{l}\text { Open business } \\
\text { platform }\end{array}$ & $\checkmark$ & & & $\checkmark$ & & \\
\hline
\end{tabular}

\begin{tabular}{|c|c|c|c|c|c|c|}
\hline Analysis criteria & [26] & [27] & [28] & [29] & [30] & [31] \\
\hline User friendliness & $\checkmark$ & $\checkmark$ & $\checkmark$ & $\checkmark$ & & \\
\hline Social networking & $\checkmark$ & & & $\checkmark$ & & \\
\hline $\begin{array}{l}\text { New skills } \\
\text { development }\end{array}$ & & & & & $\checkmark$ & $\checkmark$ \\
\hline
\end{tabular}

From the analyzed research papers, it has been found that there are three main social factors that SMEs must consider when deciding to adopt cloud computing (see Table V). The key factor to go forward with a new technology is certainly the system's user friendliness. In Mauritius, the SMEDA reveals that the level of IT education is relatively low. Hence, user friendliness remains a very important factor in decision making. Other factors that are influential are the system's ability to network with the community and for personal learning and skills development.

Table VI summarizes the technological features that impact SMEs to make a decision on cloud adoption. It can be viewed that reliability, scalability and flexibility are decisive technological factors. On the other hand, not all researchers find efficiency as a key factor to guide SMEs in cloud adoption. In Mauritius, however, the SMEDA sensitizes SMEs to choose tools that will help them to become efficient and think in the long run for the business.

\begin{tabular}{|} 
TABLE VI: TECHNOLOGICAL ANALYSIS \\
\begin{tabular}{|l|c|c|c|c|c|c|}
\hline \multicolumn{1}{|c|}{ Reference } & [12] & [27] & [26] & [20] & [29] & [18] \\
\hline Analysis criteria & & $\checkmark$ & & & & \\
\hline Efficiency & $\checkmark$ & $\checkmark$ & & $\checkmark$ & & \\
\hline Reliability & & $\checkmark$ & $\checkmark$ & $\checkmark$ & & $\checkmark$ \\
\hline Scalability & & $\checkmark$ & & $\checkmark$ & & $\checkmark$ \\
\hline Flexibility & $\checkmark$ & & & $\checkmark$ & & \\
\hline Quality & & & $\checkmark$ & & $\checkmark$ & $\checkmark$ \\
\hline Additional services & & & $\checkmark$ & & & \\
\hline
\end{tabular}
\end{tabular}

\section{PEST ANALYSIS OF MAURITIAN SMES}

\section{A. PEST Framework for Assessment}

Table VII summarizes the various factors considered for the PEST framework that are applicable in the Mauritian context. The PEST Framework addresses external factors which can be used to assess whether SMEs are ready to adopt Cloud Computing.

\section{TABLE VII: PEST FRAMEWORK FOR ASSESSMENT}

\begin{tabular}{|c|c|}
\hline $\begin{array}{ll}\text { Political } \\
\text { - } & \text { Data Protection } \\
\text { - } & \text { Regulatory framework } \\
\text { - } & \text { Initiatives to accelerate SMEs } \\
\text { - use of broadband } \\
\text { - } \\
\text { - Savorable tax treatment } \\
\text { concept }\end{array}$ & $\begin{array}{ll}\text { Economical } \\
\text { - } & \text { Affordable price } \\
\text { - } & \text { Cost reduction } \\
\text { - } & \text { Competitive advantage } \\
\text { - } & \text { Green technology } \\
\text { - } & \text { Better security } \\
\text { - } & \text { Open business platform }\end{array}$ \\
\hline $\begin{array}{l}\text { Social } \\
\text { - } \quad \text { User friendliness } \\
\text { - } \quad \text { Social networking } \\
\text { - } \quad \text { New skills development }\end{array}$ & \begin{tabular}{ll}
\multicolumn{2}{l}{ Technological } \\
- & Efficiency \\
- & Reliability \\
- & Flexibility \\
- & Scalability \\
- & Quality \\
- & Additional services \\
\end{tabular} \\
\hline
\end{tabular}

\section{B. Results and Discussion}

\section{1) Political factors}

Currently in Mauritius the Data Protection Act caters for data protection and legal definition of personal information privacy and management. However more legislative requirements are needed, particularly those concerning the conditions under which data can be stored and processed for cloud computing;

Politicians are looking for regulatory models as alternatives to the past monopolies, recognizing that the unregulated infrastructure has led to new kinds of monopolies, controlled by the strongest service providers. For instance, the government in Mauritius encourages SMEs by giving them a high percentage of tenders while compared to tendering projects to large industries. Policy initiatives to accelerate SMEs use of broadband could include favorable tax treatment, in a supportive legal, political and fiscal 
environment. For example, the Mauritian government favors cloud computing and allows SMEs to become visible online by promoting relatively inexpensive cloud platform package to them.

\section{2) Economic factors}

The Mauritian economy has experienced a relatively stable trend together with improved standard of living in the country since the last decade. The cost of internet connection for instance has drastically become less expensive while the bandwidth has increased enormously together with speed to access information online. In fact, when an SME decides to adopt cloud computing, the cost is very important, especially for start-ups. In an economy which is unstable, businesses are unlikely to invest on new technologies [32].

Moreover, with cloud computing, there is the aspect of green technology as hardware capacity is being used wisely and economically. With respect to Mauritian SMEs, having practically no budget for technology investment, cloud computing remains the primary choice as technology as affordable price.

\section{3) Social factors}

Social factors impact a lot when taking a decision with respect to ICT adoption. In fact, user friendliness of a system determines if the user will go forward with the technology or not In the Mauritian context, with SMEs having relatively very basic knowledge of IT [2], user friendliness is a decisive factor for those small organizations when it comes to cloud adoption.

In addition, cloud computing allows social networking since new opportunities crop up between business partners. When it comes to Mauritian SMEs, it all depends on the mindset of each particular organization on whether they perceive networking and partnership with other SMEs as an opening or a threat.

\section{4) Technological factors}

When it comes to cloud computing, the technological aspect of the whole architecture cannot be ignored. The client will expect the system to be robust, flexible, reliable and efficient. Besides, quality is a factor that cannot be bypassed as it foresees the long run performance of the business.

TABLE VIII: PEST ANALYSIS FOR MAURITIAN SMES

\begin{tabular}{|c|c|c|}
\hline \multicolumn{2}{|r|}{ Factors } & Analysis findings \\
\hline \multirow{4}{*}{ Political } & Data Protection & $\begin{array}{l}\text { Data protection provision by the government is a plus for the SMEs to go towards cloud computing } \\
\text { Legislation available for data processing, storage and information privacy and management. In Mauritius, } \\
\text { the data protection act is assured by the ICTA. }\end{array}$ \\
\hline & Regulatory framework & $\begin{array}{l}\text { Regulatory models are proposed. In the Mauritian context, the government favors SMEs against large } \\
\text { firms when tenders are procured. }\end{array}$ \\
\hline & $\begin{array}{l}\text { Initiatives to accelerate SMEs } \\
\text { use of broadband }\end{array}$ & $\begin{array}{l}\text { Affordable Cloud computing package set-up by the Mauritian government for SMEs in the budget report } \\
\text { 2013-2014. }\end{array}$ \\
\hline & $\begin{array}{l}\text { Sustainable development } \\
\text { concept }\end{array}$ & Contributes to significantly reducing carbon emissions. \\
\hline \multirow{6}{*}{ Economical } & Affordable price & Flexible payment (e.g. pay-per-use). \\
\hline & Costs reduction & $\begin{array}{l}\text { Cloud computing solutions will minimize the SMEs investment in own hardware (HW), software (SW) } \\
\text { and maintenance. }\end{array}$ \\
\hline & Competitive advantage & $\begin{array}{l}\text { Strategy and competitive advantage does not seem to be as relevant to the SMEs as it may be to the larger } \\
\text { organization, because their approach is life-time rather than short-time. }\end{array}$ \\
\hline & $\begin{array}{l}\text { Green technology concept } \\
\text { promotes an increase in } \\
\text { productivity }\end{array}$ & $\begin{array}{l}\text { As per the Mauritian government budget report for the year 2013-2014, SMEs should invest in smart } \\
\text { infrastructure and green technology. }\end{array}$ \\
\hline & Better security & Greater security is possible due to economies of scale plus stable economic condition in Mauritius. \\
\hline & Open business platform & $\begin{array}{l}\text { In general, cloud-computing services provide an open business platform for everyone, everywhere, for } \\
\text { every country, for every company, for every organization and for every kind of business. }\end{array}$ \\
\hline \multirow{3}{*}{ Social } & User friendliness & $\begin{array}{l}\text { A community of local players, together with distributed virtual communities, gives to the improvement of } \\
\text { tactics, technological solutions, digital services and business models. }\end{array}$ \\
\hline & Social networking & $\begin{array}{l}\text { New chances for partnership and social networking between business partners that are time and distance } \\
\text { independent. }\end{array}$ \\
\hline & New skills development & $\begin{array}{l}\text { Working with new and potentially prestigious technology, lead to career progression and increased job } \\
\text { satisfaction. }\end{array}$ \\
\hline \multirow{6}{*}{ Technological } & Efficiency & Offers a definite level of customization and allows an efficient operation. \\
\hline & Reliability & Reliability is enhanced through the use of redundant sites. \\
\hline & Scalability & Scalability is accessible through active provisioning of resources. \\
\hline & Flexibility & Provides flexible response to change. \\
\hline & Quality & $\begin{array}{l}\text { Service with high quality, always accessible anytime, at any device (mobile and fixed), at any connection } \\
\text { (via fixed and wireless connections) and from any place. }\end{array}$ \\
\hline & Additional services & $\begin{array}{l}\text { SMEs do not have to maintain and upgrade servers, applications (the software) and security. Basic } \\
\text { common services include systems for electronic payment, for certification and trust, enterprise resource } \\
\text { planning, customer relationship management, e-procurement. }\end{array}$ \\
\hline
\end{tabular}

However, the quality factor is highly ignored by Mauritian SMEs as they have the tendency to perceive their business performance and growth in the short run [2]. Therefore, in the Mauritian context, the quality criterion is less influential.

Based on the different criteria identified in the PEST analysis, Table VIII summarizes findings so as to come up with a framework suitable for Mauritian SMEs.

From Table VIII, it can be perceived that the involvements of SMEs investing in advanced tools, such as Cloud
Computing, should deliver extra indication regarding configurations of adoption. It becomes clear from the PEST analysis that the developing systems of Cloud Computing have the prospective to multiply the productivity, efficiency and profitability of start-ups.

However, some SMEs stay opposed to avail themselves of broadband services, or consider the possible advantages of Cloud Computing, due to sensitivities (or misunderstandings) vis-à-vis potential capital investment, skepticism of 
complexity, nonexistence of understanding of the potential benefits, and lack of technical resources. Others are more willing to test broadband or Cloud applications, but do not see it as part of a larger strategy. Evidence is also evolving to advocate that even large companies (opposing to conservative perception) are actually approving Cloud services. Subsequently, an increasing number of companies (small and large) are beginning to see some real value in using the Cloud.

\section{CONCLUSION AND FUTURE WORK}

There are many openings and advantages for SMEs in using Cloud Computing, such as opportunities to test new software, evaluate third party applications, increase resources on demand to satisfy seasonal or temporary demand and offer software to customers as SaaS. Other profits include time saved dealing with technology matters, allowing staff to concentrate on essential capabilities. Many of the same functions can be performed quicker and more efficiently by using modern IT structure and software than traditional in-place data centers. As a result, Cloud computing is prospective to be a smart option for many SMEs, particularly in the current global economic crisis, due to its supple cost structure and scalability.

Besides, in the specific case of SMEs, access to Cloud services is becoming a critical component for their competitiveness and efficiency. Contrariwise, absence of access would infer that the SME sector will not attain its complete potential. In nutshell, Cloud Computing services provide an open business platform for everyone, everywhere, for every country, for every company, for every organization and for every kind of business and new opportunities for partnership and social networking between business partners, by empowering access to sources of information that are time and distance independent.

The PEST factors can be regarded as a mixture of both openings and threats. Nonetheless, this methodology addresses merely exterior aspects and their impact on organization's performance, not taking into consideration the role that in-house variables can play in this framework. In this sense and for future research, a SWOT analysis is endorsed, when studying the fusion of internal and external factors with reference to the adoption of Cloud Computing by SMEs.

\section{ACKNOWLEDGMENT}

The authors gratefully acknowledge SMEDA for having given a more detailed view on how niche market operates in Mauritius and providing us relevant information for this study.

\section{REFERENCES}

[1] T. Surcel and F. Alecu, "Applications of cloud computing," in Proc. the International Conference of Science and Technology in the Context of the Sustainable Development, 2008, pp. 177-180.

[2] Small and Medium Enterprises Development Authority, SMEDA, Mauritius, 2014.

[3] Jon Brodkin. Gartner: Seven cloud computing security risks. Network World. [Online]. Available: http://www.infoworld.com/d/security-central/gartner-seven-cloud-co mputing-security-risks-853.

[4] D. Kondo, B. Javadi et al., "BCost-benefit analysis of cloud computing versus desktop grids," presented at the IEEE International Symposium on Parallel and Distributed Processing, Rome, Italy, May 2009.
[5] H. Yang and M. Tate, "Where are we at the cloud computing? A descriptive literature review," presented at $20^{\text {th }}$ Australian Conference on Information Systems, Australia, December 2009.

[6] S. Alam, "ICT adoption in small and medium enterprises: An empirical evidence of service sectors in Malaysia," International Journal of Business \& Management, vol. 4, no. 2, pp. 67-72, 2009.

[7] R. J. Barro and X. Sala-i-Martin, Economic Growth, NY: McGraw-Hill, 1995.

[8] ACA Research. Software as a service (SaaS) in Australia: Is it the next big thing? [Online]. Available: http://epress.lib.uts.edu.au/research/bitstream/handle/10453/12620/20 09001962OK.pdf?sequence $=1$.

[9] A. Greenberg, "FORBES: Computing in the cloud (Layered Tech)," Forbes Magazine, March 2008.

[10] B. Vorley, M. Hundy, and J. McGregor, "Business models for small farmers and SMEs," International Institute for Environment and Development Lundy, January 2014.

[11] TechRepublic. ZDNet \& BNET. Cloud computing - What is its potential value for your company? [Online]. Available: http://www.ltech.com/wp-content/themes/optimize/download/CloudP otentialValue.pdf.

[12] S. Sultan, "Cloud computing for education: A new dawn?" International Journal of Information Management, vol. 31, no. 3, pp. 272-278, 2011.

[13] P. Mell and T. Grance, "The NIST definition of cloud computing, distributed systems," National Institute of Standards and Technology, Information Technology Laboratory, pp. 283-298, 2011.

[14] V. Chang, D. Bacigalupo, G. Wills, and D. D. Roure, "A categorization of cloud business models," presented at $10^{\text {th }}$ IEEE/ACM International Symposium on Cloud \& Grid Computing, May 2010.

[15] K. Ohno, "Report on Mauritius mission," presented at the Fifth Tokyo International Conference on African Development, June 2013.

[16] H. Arksey and L. O'Malley, "Scoping studies: Towards a methodological framework," International Journal of Social Research Methodology: Theory and Practice, vol. 8, no. 1, pp. 19-32, 2005.

[17] PEST analysis: Understanding "Big Picture" forces of change. (May 2012). [Online]. Available: http://victechuniversity.net/pest-analysis-understanding-big-picture-fo rces-of-change/.

[18] C. S. Chien and J. Chien, Insight to Cloud Computing and Growing Impacts Information Computing and Applications, Springer, 2010, vol. 105 , pp. 250-257.

[19] K. Jayakar et al., Small Businesses and Broadband: Key Drivers for Economic Recovery, University Park, PA, 2010.

[20] C. Kloch, E. B. Petersen, and O. B. Madsen, "Cloud based infrastructure, the new business possibilities and barriers," Wireless Personal Communications, vol. 58, no. 1, pp. 17-30, 2011.

[21] A. Petrakou, P. Brandt, R. Gustavsson, and P. Jokela, "Collaborative e-Marketplaces containing clusters of SMEs: Drivers and barriers in the local food sector," presented at the $44^{\text {th }}$ Hawaii International Conference on System Sciences (HICSS), Jan. 2011.

[22] N. K. Hanna, "A holistic framework for enterprise and social transformation," Enabling Enterprise Transformation, New York: Springer, 2010, pp. 217-266.

[23] R. Gagliardi, F. Marcantoni, A. Polzonetti, B. Re, and P. Tapanelli, "Cloud computing for network business ecosystem," in Proc. 2010 IEEE International Conference on Industrial Engineering and Engineering Management (IEEM), Dec. 2010.

[24] D. Martinovic and V. Ralevic, "Canadian and UK perspectives on electronic business data transfer," presented at 2009 IEEE Toronto International Conference-Science and Technology for Humanity, TIC-STH Symposium on Information Assurance in Security and Privacy, Ryerson University, Toronto, Canada, Sept. 2009.

[25] O. S. Tumer, "Digital ecosystems \& co-innovation towards sustainable societies," presented at the $4^{\text {th }}$ IEEE International Conference on digital Ecosystems and Technologies (DEST), April 2010.

[26] M. A. Williams, "Privacy management, the law and business strategies: A case for privacy driven design," presented at the International Conference on Computational Science and Engineering, Aug 2009.

[27] F. Daneshgar, L. Worasinchai, and G. Low, "An investigation of 'Build vs. Buy' decision for software acquisition in small to medium enterprises," presented at the Society of Interdisciplinary Business Research Conference on Interdisciplinary Business Research, June 2011.

[28] T. Dimitrakos, "Common capabilities for service oriented infrastructures and platforms: An overview," presented at the IEEE $8^{\text {th }}$ European Conference on Web Services (ECOWS), Dec. 2010.

[29] R. Gagliardi et al., "Cloud computing for network business ecosystem," presented at the IEEE International Conference on Industrial Engineering and Engineering Management (IEEM), Dec 2010. 
[30] A. Khajeh-Hosseini, D. Greenwood, and I. Sommerville, "Cloud migration: A case study of migrating an enterprise IT system to IaaS", presented at the IEEE $3^{\text {rd }}$ International Conference on Cloud Computing, July 2010.

[31] J. Chen and H. Song, "Industrial clusters' information based on SaaS model," presented at the International Conference on Business Management and Electronic Information (BMEI), May 2011.

[32] R. Barro and X. Sala-i-Martin, Economic Growth, $2^{\text {nd }}$ Edition, Cambridge, Massachusetts: The MIT Press, 2004.

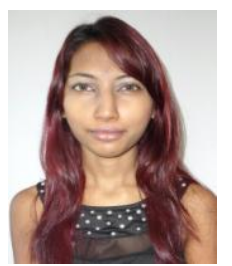

Antoo Mira is from Mauritius and was born on the $30^{\text {th }}$ of November 1989. She has completed her undergraduate degree, BSc (Honors) computer science and engineering at the University of Mauritius in the year 2011. She is currently doing her postgraduate degree in the field of computer science an engineering: MSc Software Engineering projects and Management at the University of Mauritius.

She is actually working as a senior software engineer at Nabla Business Solutions Ltd at Pointe aux Sables, Mauritius, a subsidiary of Automated Outsourcing Services (pty) Ltd, South Africa.

Ms. Antoo is a member of the Mauritius Software Craftsmanship Community.

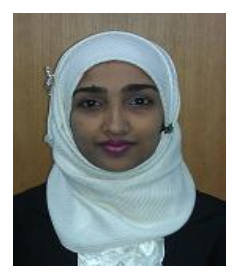

Zarine Cadersaib was born in Mauritius. She has a BEng(Hons) in computer science and engineering from the University of Mauritius awarded in 2002.

She worked as a senior programmer and an analyst programmer at DCDMC/Accenture Mauritius Ltd from 2002-2006 before joining the University of Mauritius as a lecturer in 2006 (till date). Her research interests include context aware applications, enterprise systems, EAI and cloud computing. She has some publications in conference proceedings and journal articles and she also designed a distance learning manual on Management Information systems for the University of Mauritius in 2009 .

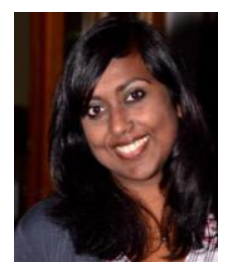

Baby A. Gobin is a lecturer in the Department of Computer Science and Engineering at the University of Mauritius since 2009. She has a BSc.(Hons) in computer science and engineering, an MSc. in ebusiness and is completing her $\mathrm{PhD}$ in computer science. Her research thesis discusses on a new and agile approach to develop ontology modules.

She is also the founder and chairperson of the ITS Research and Consultancy Group which has as aim to investigate and promote the use of IT in the Mauritius. The group is currently working on two projects. The first one is the implementation of Information Systems at the National Empowerment Foundation, a body working for the empowerment of households, which are under the threshold of poverty. The second project is a study on technology acceptance among small and medium enterprises. This project is being done in collaborating with the SMEDA, a parastatal body set up by the government of Mauritius to help SMEs. 